OPEN ACCESS

Edited by:

Martin Grube,

University of Graz, Austria

Reviewed by:

Shengguo Zhao, Institute of Animal Science, Chinese Academy of Agricultural Sciences,

China

Daria Rybakova

Graz University of Technology, Austria

*Correspondence:

Chun-Jie L

chunjie@/zu.edu.cn

Specialty section:

This article was submitted to

Microbial Symbioses,

a section of the journal

Frontiers in Microbiology

Received: 07 April 2016 Accepted: 29 November 2017 Published: 15 December 2017

Citation:

Li X-Z, Song M-L, Yao X, Chai $Q$, Simpson WR, Li C-J and Nan Z-B (2017) The Effect of Seed-Borne Fungi and Epichloë Endophyte on Seed

Germination and Biomass of Elymus sibiricus. Front. Microbiol. 8:2488, doi: 10.3389/fmicb.2017.02488

\section{The Effect of Seed-Borne Fungi and Epichloë Endophyte on Seed Germination and Biomass of Elymus sibiricus}

\author{
Xiu-Zhang Li ${ }^{1}$, Mei-Ling Song ${ }^{1}$, Xiang Yao ${ }^{1}$, Qing Chai ${ }^{1}$, Wayne R. Simpson ${ }^{2}$, \\ Chun-Jie $\mathrm{Li}^{1 *}$ and Zhi-Biao Nan ${ }^{1}$
}

'State Key Laboratory of Grassland Agro-Ecosystems, Key Laboratory of Grassland Livestock Industry Innovation, Ministry of Agriculture, College of Pastoral Agriculture Science and Technology, Lanzhou University, Lanzhou, China, ${ }^{2}$ AgResearch Grasslands Research Centre, Tennent Drive, Palmerston North, New Zealand

The interactive effects of asexual Epichloë (formerly known as Neotyphodium) endophytes isolated from Hordeum brevisubulatum, Elymus tangutorum and Achnatherum inebrians, and seed-borne fungi on Elymus sibiricus seeds, were determined by an in vitro study using supernatants from liquid cultures of the endophyte strains. In an 8 week greenhouse study, the effects on the seedlings growth was measured. The in vitro study was carried out with the seed-borne fungi Alternaria alternata, Bipolaris sorokiniana, Fusarium avenaceum, and a Fusarium sp. isolated from E. sibiricus. Different concentrations and combinations of the liquid cultures of endophytic fungi enhanced the interim germination, germination rate, length of coleoptile and radicle, and seedling dry weight of $E$. sibiricus under stress from seed-borne fungi. In the greenhouse study, different concentrations of the supernatant of the endophytes from $H$. brevisubulatum and $E$. tangutorum but not $A$. inebrians, signficantly $(P<0.05)$ enhanced $E$. sibiricus seed germination. There was no significant $(P>0.05)$ increase of the tiller numbers after 2 weeks. However, later on, there were significant $(P<0.05)$ increases in tiller number (4-8 weeks), seedling height (2-8 weeks) and dry weight (2-8 weeks). The application of Epichloë endophyte culture supernatants was an effective strategy to improve seed germination and growth under greenhouse conditions.

Keywords: Epichloë endophyte, Elymus sibiricus, seed-borne fungi, seed germination, Elymus tangutorum, Achnatherum inebrians, seedling, dry weight

\section{INTRODUCTION}

Endophytic fungal associations with grasses are very common, and the most intensively studied are those between ascomycete fungi and temperate grasses, in particular those involving asexual endophytes of the genus Epichloë (Schardl, 2001; Schardl et al., 2004). Asexual or anamorph-typified Epichloë have a common origin with the sexual Epichloë or teleomorphtypified species (Kuldau et al., 1997; van Zijll de Jong et al., 2011; Leuchtmann et al., 2014). Teleomorph-typified Epichloë species are sexually reproducing and cause a condition known as "choke" in grasses, whereby the fungal stromata formed during sexual reproduction leads to 
reduced flower and seed production (Schardl et al., 2004). The host range of symbiotic fungal endophytes has been described in cool-season grasses (Leuchtmann, 1993; Scott, 2001). Fungal endophytes are of increasing interest due to a growing list of benefits that they can confer on their hosts, including both abiotic and biotic factors such as tolerance to drought (Malinowski and Belesky, 2000; Clay and Schardl, 2002; Hahn et al., 2008), resistance to insects, nematodes and other herbivorous attacks (Omacini et al., 2001; Schardl et al., 2004; Schardl, 2009; Zhang et al., 2012) including bird deterrence (Pennell et al., 2010; Pennell and Rolston, 2012).

Besides that, Epichloë endophytes can increase tolerance to pathogenic fungi, although the deployment of Epichloë as agents for the biological control of diseases has shown mixed results (Kuldau and Bacon, 2008). in vitro suppression of plant pathogens by endophytic fungi has been demonstrated (White and Cole, 1985; Holzmann-Wirth et al., 2000), there is some evidence showing that colony growth of plant-pathogenic fungi is inhibited by Epichloë endophytes (Christensen and Latch, 1991; Christensen, 1996; Wäli et al., 2006) and that disease tolerance or resistance can be imparted by Epichloë species (Li et al., 2007b; Tian et al., 2008; Porras-Alfaro and Bayman, 2010). The name Epichloë gansuensis (Neotyphodium gansuense) was proposed by Chunjie Li and Zhibiao Nan (Li et al., 2004; Leuchtmann et al., 2014) for an endophytic fungus symbiotic with A. inebrians from Gansu, China. Dual-culture testing and inoculation of detached leaves have shown that E. gansuensis can inhibit growth and disease lesion development of some fungal pathogens ( $\mathrm{Li}$ et al., 2007a).

At present, although many of the mechanisms of the interaction between Epichloë and fungal pathogens are not clear, it is reported that several pathogenic fungi are controlled to some level by endophyte infection in vitro: Alternaria alternata, A. triticina, Bipolaris sorokiniana, Cladosporium spp. including C. cladosporioides, Curvularia spp. including C. lunata, Drechslera erythrospila, Fusarium acuminatum, Phomopsis spp., Rhizoctonia cerealis, and R. zeae (White and Cole, 1985; Gwinn and Bernard, 1988; Holzmann-Wirth et al., 2000; Li et al., 2007b; Xie et al., 2008). Compared with un-infected grasses of Agropyron cristatum, Elymus cylindricus, and Festuca rubra, Epichloë endophyte can reduce the numbers of Alternaria, Cladosporium, and Fusarium species on leaves of host grasses (Nan and Li, 2000). Vignale et al. report that E. pampeana (N. pampeanum) and E. tembladerae ( $N$. tembladerae) can protect their host plant Bromus auleticus against the pathogenic fungus Ustilago bullata (Vignale et al., 2013). Other studies have demonstrated inhibitory effects in vivo against Ascochyta leptospora, F. avenaceum, F. chlamydosporum, F. culmorum, F. oxysporum, F. solani, Gliocladium roseum, Laetisaria fuciformis, and Sclerotinia homeocarpa (Bonos et al., 2005; Clarke et al., 2006; Li et al., 2007b; Tian et al., 2008).

Elymus sibiricus (Siberian wildrye) is a perennial, caespitose grass, widely distributed around the world (Ma et al., 2012). It usually grows on arid or semiarid mountain or valley grasslands at altitudes from 1,000 to $4,000 \mathrm{~m}$ in northwestern China. It has also played an important role in native grassland restoration on the Qinghai-Tibet Plateau of China as a pioneer grass species
(Ma et al., 2012). E. sibiricus usually serves as an important forage grass, and has been widely employed in establishing sown grasslands to develop stock raising, due to its strong adaptability, excellent tolerance to drought and cold, high crude protein content, and good palatability (Yan et al., 2007). However, the pathogenic fungus of seed-borne is important factor to limit the host E. sibiricus germination and seedling growth ( $\mathrm{Li}$ et al., 2007b).

Presently much of the research involving Epichloë is concentrated on the relationship with the host grass, secondary metabolites, interaction mechanisms, taxonomy and ecology. Here we examine Epichloë endophytes isolated from three species of grass and seed-borne fungi isolated from E. sibiricus. The effect of endophytic liquid medium exudate on E. sibiricus germination under a seed-borne fungus burden is examined to provide a theoretical basis for the rational use of Epichloë endophytes in the field.

\section{MATERIALS AND METHODS}

\section{Epichloë Endophyte Biological Material}

Epichloë gansuensis (N. gansuense) (CBS 119808, ATCC-MYA3669) was isolated from stems of A. inebrians from Sunan, Gansu Province, China (Li et al., 2007b). Epichloë/Neotyphodium spp. isolated from $H$. brevisubulatum and E. tangutorum were marked as Eb and Et, and the Epichloë gansuensis was marked as Eg. The H. brevisubulatum and E. tangutorum samples were collected from Linze $\left(\mathrm{E}: 102^{\circ} 54^{\prime}, \mathrm{N}: 37^{\circ} 29^{\prime} ; 1,450 \mathrm{~m}\right)$ and Lanzhou $\left(\mathrm{E} 103^{\circ} 56^{\prime}, \mathrm{N}^{\circ} 6^{\circ} 01^{\prime} ; 1,714 \mathrm{~m}\right)$, Gansu Province, China in 2012 (Song and Nan, 2015; Song et al., 2015).

A $4 \mathrm{~mm}$ diam plug of 1 week-old endophytic fungus grown on potato dextrose agar (PDA) was used to inoculate $150 \mathrm{~mL}$ flasks of potato dextrose broth (PDB) nutrient medium, with 3 repetitions of each strain. Four weeks later, the broth was filtered and centrifuged. The filtrate was diluted to 50 and $25 \%$. The sample of endophytic fungi was marked as Eb01, Eb02, Eb03, Et01, Et02, Et03, Eg01, Eg02 and Eg03, 01 is 25\% diluted, 02 is $50 \%$ and 03 is undiluted.

\section{E. sibiricus Sample and the Seed-Borne Fungi}

The E. sibiricus seed sample was collected from from Sunan (E99 $38^{\prime}, \mathrm{N}^{\circ} 8^{\circ} 50^{\prime}$; 2,233 m), Gansu Province, China. Ten seeds were inoculated to each of 10 Petri plates $(9 \mathrm{~cm}$ diameter) containing PDA, then incubated at $22 \pm 1{ }^{\circ} \mathrm{C}$ in the dark. Observation was made of fungal colony growth on the seed, colonies were picked off to clean PDA plates, and subsequently identified. The 4 fungal strains use in this test were identified as $A$. alternata, $B$. sorokiniana, $F$. avenaceum along with an unidentified Fusarium species. Ten replicates of each strain were cultured for 1 week on PDA.

Sterile water was added to the cultures and a spore suspension produced. The spore suspension was micropore filtered. Conidial concentration was determined using a blood count plate and suspensions adjusted to spore concentrations no $<10^{6} / \mathrm{mL}$. Adjusted spore suspensions were maintained at $4{ }^{\circ} \mathrm{C}$ in conical flasks. All isolates of Epichloë spp. and fungal pathogens 
were deposited at the Mycological Herbarium of Lanzhou University.

\section{Effects of the Endophytic Fungi Supernatant on Germination and Seedling Growth under Seed-Borne Fungi Stress}

Seeds were surface sterilized in $75 \%$ ethanol (v/v) for $5 \mathrm{~min}$ and $5 \%$ sodium hypochlorite for $10 \mathrm{~min}$, then washed with sterile water 3 times. The seeds were then placed into a centrifuge tube with $15 \mathrm{ml}$ of the endophytic fungi supernatant and imbibed for $12 \mathrm{~h}$ under axenic conditions. The control was a centrifuge tube containing the same amount of sterilized water. Seed was incubated in the dark with ventilation. Incubate seed is dry, then sow on two layers of sterile filter paper in a $90 \mathrm{~mm}$ glass Petri dish with $5 \mathrm{ml}$ of spore suspension of seed-borne fungi. Each treatment consisted of 4 replicates, for a total of 200 seeds. According to the method of ISTA (1996), all of the seeds were incubated in a growth chamber $\left(25 \pm 1^{\circ} \mathrm{C}, 24 \mathrm{~h}\right.$ illumination $)$, with sterile distilled water $(5 \mathrm{~mL})$ added to each Petri plate every 2 days using a disposable syringe. Germination potential was noted on day 6 , percentage of germination on day 12 . After 12 day, the radicle length (RL), coleoptile length $(\mathrm{CL})$ and dry weight were measured. The dry weight was obtained after drying at $75^{\circ} \mathrm{C}$ until a constant weight was recorded (to $0.0001 \mathrm{~g}$ ) with an electronic balance. The radicle length (RL) and coleoptile length (CL) were measured by Vernier calipers. The above characteristics were calculated by the formula: Interim germination $=$ (the number of germinated seeds at 6 day/total number of seed) $\times 100 \%$; Germination rate $(\mathrm{GR})=($ the number of germinated seeds at 12 day/total number of seed) $\times 100 \%$; Vigor index $(\mathrm{VI})=($ the number of germinated seeds at 6 day $/ 6^{*}$ length of radicle) $\times 100 \%$.

\section{Effects of the Endophytic Fungi Supernatant on Plant Growth under Greenhouse Conditions}

Uniform, plump seeds were selected and soaked in the Eb03, Et03, and Et02 for $12 \mathrm{~h}$ under axenic condition, from this, three supernatant samples were chosen because of they have the effect with high germination rate of the seed. The control consisted of a centrifuge tube containing the same amount of sterilized water. The seed was incubated in the dark with ventilation. Seed was dried and sown into plastic pots $(12 \mathrm{~cm}$ diameter $\times$ $10 \mathrm{~cm}$ depth) containing sterile soil (Junzilan, Lanzhou, China), watered as needed, and grown under controlled greenhouse conditions $\left(22 / 18^{\circ} \mathrm{C}\right.$, day/night; sunlight; $65 \%$ relative humidity. Each treatment was repeated 5 times independently. Plant height and tiller number were recorded every 2 weeks for 8 weeks. Seedling biomass was harvested after 8 weeks, dried at $75^{\circ} \mathrm{C}$ and weighted until a constant was recorded.

\section{Statistical Analysis}

The data were analyzed for variance (ANOVA) and least significant difference (LSD) using SPSS. 19.0 software (SPSS Inc., Chicago, IL, USA).

\section{RESULTS}

\section{Effects of the Endophytic Fungi Supernatant on Germination and Seedling Growth under Seed-Borne Fungi Stress}

Exudates of the 9 endophytic fungi in supernatant when applied to seed were able to enhance interim germination under seed-borne fungi stress, the seed germination was differs under different endophytic fungi sample (Table 1). The seed germination is significantly $(P<005)$ higher when treated with Et supernatant compared to the treatments with $\mathrm{Eb}$ and $\mathrm{Eg}$ which resulted in higher germination than the (CK) control. For different species of seed-borne fungi, the effect of the application of endophytic fungal supernatant on interim seed germination differed. Across the range of Epichloë supernatant examined interim germination of seed exposed to seed-borne fungi A. alternata, B. sorokiniana, F. avenaceum, and Fusarium sp. is $21.47-39.13 \%$ (mean 29.30\%), $18.07-39.93 \%$ (mean 27.80\%), $13.03-28.60 \%$ (mean 19.44\%), and 13.77-33.70\% (mean $21.47 \%$ ), respectively. For most strains, as the endophytic fungi supernatant dilution was reduced, the interim germination of seed under seed-borne fungi stress increased. However, the seed germination rate decreased with the increase of concentration of endophytic fungi treated by Eg under all of the seed-borne fungi and Eb03 under Fusarium sp.

The germination rate of the E. sibiricus seeds imbibed in endophytic fungi supernatant was significantly $(P<0.05)$ higher than the control (Table 2). Germination rate of the seed of E. sibiricus under seed-borne fungi stress increased with increasing endophytic fungi supernatant concentration except for Eb and Eg. With the increase of concentration of endophytic fungi supernatant of $\mathrm{Eb}$, the germination rate under seedborne fungi stress of $B$. sorokiniana and $F$. avenaceum was higher at first then descended as concentration increased. Eg also showed a higher germination rate across all the seedborne fungi treatments, but as concentration of the supernatant

TABLE 1 | Interim Germination (\%) of Elymus sibiricus under seed-borne fungi stress resulting from effects of the Epichloë endophyte.

\begin{tabular}{lcccc}
\hline & A. alternata & B. sorokiniana & F avenaceum & Fusarium sp. \\
\hline CK & $22.50 \pm 0.96 \mathrm{Ea}$ & $19.50 \pm 2.87 \mathrm{Da}$ & $11.50 \pm 0.96 \mathrm{~Eb}$ & $23.00 \pm 1.91 \mathrm{Ea}$ \\
Eb01 & $26.00 \pm 0.82 \mathrm{Db}$ & $27.50 \pm 2.06 \mathrm{Cb}$ & $17.50 \pm 1.71 \mathrm{Cc}$ & $35.00 \pm 3.42 \mathrm{Ca}$ \\
Eb02 & $31.50 \pm 0.50 \mathrm{Cb}$ & $28.50 \pm 1.89 \mathrm{Cbc}$ & $23.00 \pm 1.73 \mathrm{Bc}$ & $46.00 \pm 3.46 \mathrm{Ba}$ \\
Eb03 & $34.50 \pm 0.50 \mathrm{Bb}$ & $30.00 \pm 0.82 \mathrm{Cb}$ & $24.50 \pm 1.26 \mathrm{Bc}$ & $49.00 \pm 2.52 \mathrm{Ba}$ \\
Et01 & $26.00 \pm 0.82 \mathrm{Db}$ & $25.50 \pm 1.26 \mathrm{Cb}$ & $18.00 \pm 0.82 \mathrm{Cc}$ & $36.00 \pm 1.63 \mathrm{Ca}$ \\
Et02 & $36.50 \pm 1.71 \mathrm{Bb}$ & $35.50 \pm 1.26 \mathrm{Bb}$ & $24.00 \pm 0.82 \mathrm{Bc}$ & $48.00 \pm 1.63 \mathrm{Ba}$ \\
Et03 & $39.50 \pm 0.96 \mathrm{Ab}$ & $40.00 \pm 0.82 \mathrm{Ab}$ & $28.50 \pm 1.26 \mathrm{Ac}$ & $57.00 \pm 2.52 \mathrm{Aa}$ \\
Eg01 & $30.00 \pm 0.82 \mathrm{Ca}$ & $28.50 \pm 1.26 \mathrm{Ca}$ & $16.50 \pm 1.26 \mathrm{CDb}$ & $33.00 \pm 2.52 \mathrm{CDa}$ \\
Eg02 & $26.50 \pm 0.96 \mathrm{Db}$ & $26.00 \pm 0.82 \mathrm{Cb}$ & $17.50 \pm 1.26 \mathrm{Cb}$ & $35.00 \pm 2.52 \mathrm{Ca}$ \\
Eg03 & $21.50 \pm 0.96 \mathrm{~Eb}$ & $18.00 \pm 0.82 \mathrm{Dbc}$ & $13.50 \pm 1.26 \mathrm{Dc}$ & $27.00 \pm 2.52 \mathrm{Da}$
\end{tabular}

Values are mean ( $\pm S E$ ) of four independent replications with 50 seeds for each replication at 6 days. Significant differences at the 0.05 level in the same column are indicated by different letters $A, B, C, D, E$, and in the same row with $a, b, c .01$ is $25 \%$ diluted of Epichloë endophyte, 02 is $50 \%$ and 03 is undiluted. 
TABLE 2 | Germination rate (\%) of Elymus sibiricus under seed-borne fungi stress resulting from effects of the Epichloë endophyte.

\begin{tabular}{lllll}
\hline & A. alternata & B. sorokiniana & F. avenaceum & Fusarium sp. \\
\hline CK & $60.00 \pm 1.41 \mathrm{Da}$ & $52.00 \pm 0.82 \mathrm{~Gb}$ & $46.50 \pm 0.96 \mathrm{Fc}$ & $54.50 \pm 0.96 \mathrm{Fb}$ \\
Eb01 & $69.00 \pm 1.29 \mathrm{Ca}$ & $70.00 \pm 0.82 \mathrm{Da}$ & $69.00 \pm 1.29 \mathrm{Ca}$ & $62.00 \pm 0.82 \mathrm{~Eb}$ \\
Eb02 & $78.50 \pm 1.26 \mathrm{Ba}$ & $73.50 \pm 0.50 \mathrm{Cb}$ & $74.50 \pm 1.26 \mathrm{Bb}$ & $70.00 \pm 0.82 \mathrm{CDc}$ \\
Eb03 & $78.50 \pm 1.71 \mathrm{Ba}$ & $72.00 \pm 0.82 \mathrm{CDb}$ & $72.50 \pm 1.71 \mathrm{Bb}$ & $71.00 \pm 1.29 \mathrm{BCb}$ \\
Et01 & $75.50 \pm 0.50 \mathrm{Ba}$ & $71.50 \pm 0.50 \mathrm{CDb}$ & $66.50 \pm 0.50 \mathrm{CDc}$ & $67.50 \pm 0.50 \mathrm{Dc}$ \\
Et02 & $84.00 \pm 0.82 \mathrm{Aa}$ & $81.00 \pm 1.29 \mathrm{Bb}$ & $81.50 \pm 0.50 \mathrm{Aab}$ & $76.50 \pm 0.50 \mathrm{Ac}$ \\
Et03 & $85.50 \pm 0.96 \mathrm{Aa}$ & $84.50 \pm 0.96 \mathrm{Aa}$ & $83.50 \pm 0.50 \mathrm{Aa}$ & $78.50 \pm 0.96 \mathrm{Ab}$ \\
Eg01 & $72.00 \pm 0.82 \mathrm{Ca}$ & $67.50 \pm 0.50 \mathrm{~Eb}$ & $61.50 \pm 1.26 \mathrm{Ec}$ & $69.00 \pm 1.29 \mathrm{Cab}$ \\
Eg02 & $76.50 \pm 0.50 \mathrm{Ba}$ & $74.00 \pm 0.82 \mathrm{Cb}$ & $68.50 \pm 0.50 \mathrm{Cc}$ & $73.50 \pm 0.96 \mathrm{Bb}$ \\
Eg03 & $70.00 \pm 1.41 \mathrm{Ca}$ & $65.00 \pm 1.29 \mathrm{Fb}$ & $64.50 \pm 1.26 \mathrm{Db}$ & $68.50 \pm 1.26 \mathrm{CDab}$
\end{tabular}

Values are mean ( $\pm S E$ ) of four independent replications with 50 seeds for each replication at 12 days. Significant differences at the 0.05 level in the same column are indicated by different letters $A, B, C, D, E, F, G$, and in the same row with $a, b, c .01$ is $25 \%$ diluted of Epichloë endophyte, 02 is $50 \%$ and 03 is undiluted.

increased germination rate decreased. However, they had no significant difference $(P>0.05)$. The germination rate of the E. sibiricus seeds imbibed in Et supernatant was higher than those imbibed in the other supernatants. The germination rate of the E. sibiricus seeds imbibed in the exudates of 3 endophytic fungi, Eb, Et, and $\mathrm{Eg}$ is $62.00-78.93 \%$ (mean $71.53 \%$ ), $66.67-85.07 \%$ (mean $77.79 \%$ ), and 61.63-76.80\% (mean 69.05\%), respectively.

Coleoptile length of E. sibiricus under seed-borne fungi stress increased with increasing concentration of most endophytic fungi supernatant with the exception of the Eg exudate (Table 3). The coleoptile length of E. sibiricus seedlings generated from seed imbibed in Eg supernatant and exposed to A. alternata and Fusarium sp. increased as the concentration of Eg liquid medium increased but then decreased with increasing concentration $3.97,4.07,4.03,3.92,4.04$, and $4.01 \mathrm{~cm}$, however there was no significant difference $(P>0.05)$. The coleoptile length of seedlings generated from seed exposed to the supernatant of the 3 fungal strains were significantly $(P<0.05)$ higher than that of the control. The increase in coleoptile length observed for seedlings generated from endophytesupernatant imbibed seed under seedborne fungi burden varied. The coleoptile length of seedlings treated by Et02 and Et03 were significantly $(P<0.05)$ higher than the others, with coleoptile lengths of $4.47-4.97 \mathrm{~cm}$ (mean $4.70 \mathrm{~cm}), 4.50-4.91 \mathrm{~cm}(4.79 \mathrm{~cm})$, respectively.

Radicle length of E. sibiricus under seed-borne fungi stress increased with increasing concentration of endophytic fungi liquid medium except with Et exudate (Table 4). The radicle length of E. sibiricus under A. alternata pressure increased as the concentration of Eg exudate increased but then decreased with increasing exudate concentration however there was no significant difference $(P>0.05)$. The radicle length of $E$. sibiricus treated with Et02 and Et03 were significantly $(P<0.05)$ higher $3.41-3.92 \mathrm{~cm}$ (mean $3.71 \mathrm{~cm}$ ) and $3.86-4.08 \mathrm{~cm}$ (mean $3.99 \mathrm{~cm}$ ), than the others. The radicle length of endophyte exudate treated E. sibiricus under seed-borne fungi stress involving A. alternata, B. sorokiniana, F. avenaceum, and F. sp. was $2.15-3.33 \mathrm{~cm}$ (mean $2.84 \mathrm{~cm}$ ), $2.42-4.08 \mathrm{~cm}$ (mean $3.49 \mathrm{~cm}$ ) and $2.39-2.76 \mathrm{~cm}$ (mean
TABLE 3 | Coleoptile length (cm) of Epichloë endophyte-infected Elymus sibiricus under seed-borne fungi stress.

\begin{tabular}{lllll}
\hline & A. alternata & B. sorokiniana & F. avenaceum & Fusarium sp. \\
\hline CK & $3.11 \pm 0.03 \mathrm{Ea}$ & $3.09 \pm 0.06 \mathrm{Ea}$ & $2.87 \pm 0.05 \mathrm{Fb}$ & $3.01 \pm 0.03 \mathrm{Ea}$ \\
Eb01 & $3.59 \pm 0.05 \mathrm{Da}$ & $3.45 \pm 0.05 \mathrm{Dab}$ & $3.53 \pm 0.11 \mathrm{Ea}$ & $3.28 \pm 0.05 \mathrm{Db}$ \\
Eb02 & $4.06 \pm 0.06 \mathrm{BCa}$ & $4.01 \pm 0.09 \mathrm{BCab}$ & $3.80 \pm 0.05 \mathrm{BCDb}$ & $3.97 \pm 0.08 \mathrm{Bab}$ \\
Eb03 & $4.16 \pm 0.06 \mathrm{Ba}$ & $4.09 \pm 0.04 \mathrm{Bab}$ & $3.97 \pm 0.03 \mathrm{Bb}$ & $4.01 \pm 0.03 \mathrm{Bb}$ \\
Et01 & $3.90 \pm 0.05 \mathrm{Cab}$ & $3.94 \pm 0.05 \mathrm{BCa}$ & $3.66 \pm 0.05 \mathrm{DEb}$ & $3.69 \pm 0.11 \mathrm{Cb}$ \\
Et02 & $4.59 \pm 0.12 \mathrm{Abc}$ & $4.78 \pm 0.09 \mathrm{Aab}$ & $4.97 \pm 0.02 \mathrm{Aa}$ & $4.47 \pm 0.05 \mathrm{Ac}$ \\
Et03 & $4.71 \pm 0.08 \mathrm{Ab}$ & $4.91 \pm 0.02 \mathrm{Aa}$ & $5.04 \pm 0.06 \mathrm{Aa}$ & $4.50 \pm 0.07 \mathrm{Ac}$ \\
Eg01 & $3.97 \pm 0.03 \mathrm{BCa}$ & $3.53 \pm 0.14 \mathrm{Db}$ & $3.75 \pm 0.04 \mathrm{CDab}$ & $3.92 \pm 0.06 \mathrm{Ba}$ \\
Eg02 & $4.07 \pm 0.04 \mathrm{BCa}$ & $3.78 \pm 0.09 \mathrm{Cb}$ & $3.91 \pm 0.03 \mathrm{BCab}$ & $4.04 \pm 0.05 \mathrm{Ba}$ \\
Eg03 & $4.03 \pm 0.03 \mathrm{BCa}$ & $3.83 \pm 0.08 \mathrm{Ca}$ & $3.95 \pm 0.06 \mathrm{Ba}$ & $4.01 \pm 0.03 \mathrm{Ba}$
\end{tabular}

Values are mean $( \pm S E)$ of four independent replications with 50 seeds for each replication at 12 days. Significant differences at the 0.05 level in the same column are indicated by different letters $A, B, C, D, E$, and in the same row with $a, b, c .01$ is $25 \%$ diluted of Epichloë endophyte, 02 is $50 \%$ and 03 is undiluted.

TABLE 4 | Radicle length (cm) of Elymus sibiricus under seed-borne fungi stress resulting from effects of the Epichloë endophyte.

\begin{tabular}{lllll}
\hline & A. alternata & B. sorokiniana & F. avenaceum & Fusarium sp. \\
\hline CK & $2.14 \pm 0.04 \mathrm{Ca}$ & $2.04 \pm 0.02 \mathrm{Fab}$ & $1.92 \pm 0.04 \mathrm{~Eb}$ & $1.98 \pm 0.04 \mathrm{Fb}$ \\
Eb01 & $2.26 \pm 0.03 \mathrm{Cab}$ & $2.32 \pm 0.06 \mathrm{Ea}$ & $2.34 \pm 0.04 \mathrm{Da}$ & $2.15 \pm 0.03 \mathrm{Fb}$ \\
Eb02 & $2.93 \pm 0.16 \mathrm{Ba}$ & $3.24 \pm 0.10 \mathrm{Ba}$ & $2.99 \pm 0.07 \mathrm{Ca}$ & $3.17 \pm 0.02 \mathrm{Ca}$ \\
Eb03 & $3.03 \pm 0.04 \mathrm{Bb}$ & $3.33 \pm 0.05 \mathrm{Ba}$ & $3.08 \pm 0.02 \mathrm{Cb}$ & $3.25 \pm 0.07 \mathrm{Ca}$ \\
Et01 & $2.95 \pm 0.22 \mathrm{Ba}$ & $2.92 \pm 0.20 \mathrm{Ca}$ & $2.42 \pm 0.06 \mathrm{Da}$ & $2.76 \pm 0.13 \mathrm{Da}$ \\
Et02 & $3.88 \pm 0.15 \mathrm{Aa}$ & $3.92 \pm 0.13 \mathrm{Aa}$ & $3.41 \pm 0.09 \mathrm{Bb}$ & $3.61 \pm 0.02 \mathrm{Bab}$ \\
Et03 & $4.08 \pm 0.04 \mathrm{Aa}$ & $4.06 \pm 0.02 \mathrm{Aa}$ & $3.86 \pm 0.10 \mathrm{Aa}$ & $3.95 \pm 0.06 \mathrm{Aa}$ \\
Eg01 & $2.74 \pm 0.04 \mathrm{Ba}$ & $2.56 \pm 0.06 \mathrm{DEb}$ & $2.39 \pm 0.03 \mathrm{Dc}$ & $2.42 \pm 0.03 \mathrm{Ec}$ \\
Eg02 & $2.76 \pm 0.14 \mathrm{Ba}$ & $2.67 \pm 0.08 \mathrm{CDa}$ & $2.46 \pm 0.05 \mathrm{Da}$ & $2.50 \pm 0.08 \mathrm{Ea}$ \\
Eg03 & $2.69 \pm 0.07 \mathrm{Ba}$ & $2.71 \pm 0.08 \mathrm{CDa}$ & $2.47 \pm 0.04 \mathrm{Db}$ & $2.53 \pm 0.05 \mathrm{Eab}$
\end{tabular}

Values are mean ( $\pm S E$ ) of four independent replications with 50 seeds for each replication at 12 days. Significant differences at the 0.05 level in the same column are indicated by different letters $A, B, C, D, E, F$, and in the same row with $a, b, c .01$ is $25 \%$ diluted of Epichloë endophyte, 02 is $50 \%$ and 03 is undiluted.

$2.57 \mathrm{~cm}$ ), respectively, which was higher than the control at $1.92-2.14 \mathrm{~cm}$ (mean $2.02 \mathrm{~cm}$ ).

Dry weight of $E$. sibiricus seedlings under seed-borne fungi stress increased with increasing concentration of endophytic fungi exudate except for Eg (Table 5). The dry weight of seedlings treated with $A$. alternata and $F$. avenaceum initially increased with increasing concentration of $\mathrm{Eg}$ exudate then decreased. Treatment of B. sorokiniana stressed seedlings with Eg resulted in a relative seedling dry weight decrease, initially, followed by an increase with increasing exudate concentration, but with no significant difference $(P>0.05)$.

\section{Effects of the Endophytic Fungi Liquid Medium on Plant Growth under Greenhouse Conditions}

Plant height of E. sibiricus treated by the optimal concentration of Eb03, Et03 and Et02 was significantly $(P<0.05)$ higher than the 
TABLE 5 | Dry weight $\left(10^{-2} \mathrm{~g}\right)$ of Elymus sibiricus under seed-borne fungi stress resulting from effects of the Epichloë endophyte.

\begin{tabular}{lllll}
\hline & A. alternata & B. sorokiniana & F avenaceum & Fusarium sp. \\
\hline CK & $1.95 \pm 0.04 \mathrm{Ca}$ & $1.93 \pm 0.03 \mathrm{Fab}$ & $1.83 \pm 0.02 \mathrm{Db}$ & $1.91 \pm 0.03 \mathrm{Dab}$ \\
Eb01 & $2.12 \pm 0.02 \mathrm{ABCC} 1.98 \pm 0.07 \mathrm{EFab}$ & $1.95 \pm 0.05 \mathrm{Cb}$ & $2.01 \pm 0.02 \mathrm{BCab}$ \\
Eb02 & $2.21 \pm 0.01 \mathrm{Aa}$ & $2.17 \pm 0.02 \mathrm{BCDa}$ & $2.04 \pm 0.04 \mathrm{Bb}$ & $2.08 \pm 0.03 \mathrm{Bb}$ \\
$\mathrm{Eb03}$ & $2.23 \pm 0.06 \mathrm{Aa}$ & $2.20 \pm 0.05 \mathrm{BCab}$ & $2.07 \pm 0.02 \mathrm{Bb}$ & $2.09 \pm 0.01 \mathrm{Bb}$ \\
Et01 & $2.14 \pm 0.03 \mathrm{ABa}$ & $2.09 \pm 0.03 \mathrm{CDEab}$ & $2.02 \pm 0.03 \mathrm{BCb}$ & $2.03 \pm 0.04 \mathrm{BCab}$ \\
Et02 & $2.27 \pm 0.06 \mathrm{Aa}$ & $2.30 \pm 0.08 \mathrm{ABa}$ & $2.16 \pm 0.01 \mathrm{Aa}$ & $2.21 \pm 0.02 \mathrm{Aa}$ \\
Et03 & $2.28 \pm 0.11 \mathrm{Aa}$ & $2.35 \pm 0.06 \mathrm{Aa}$ & $2.18 \pm 0.02 \mathrm{Aa}$ & $2.23 \pm 0.02 \mathrm{Ba}$ \\
Eg01 & $1.98 \pm 0.06 \mathrm{BCa}$ & $2.05 \pm 0.04 \mathrm{DEFa}$ & $2.02 \pm 0.03 \mathrm{BCa}$ & $1.97 \pm 0.03 \mathrm{CDa}$ \\
Eg02 & $2.02 \pm 0.02 \mathrm{BCa}$ & $2.03 \pm 0.04 \mathrm{DEFa}$ & $2.05 \pm 0.02 \mathrm{Ba}$ & $1.99 \pm 0.03 \mathrm{Ca}$ \\
Eg03 & $1.97 \pm 0.03 \mathrm{Ca}$ & $2.04 \pm 0.01 \mathrm{DEFa}$ & $2.03 \pm 0.02 \mathrm{BCa}$ & $2.01 \pm 0.03 \mathrm{BCa}$
\end{tabular}

Values are mean ( \pm SE) of four independent replications with 50 seeds for each replication at 12 days. Significant differences at the 0.05 level in the same column are indicated by different letters $A, B, C, D, E, F$, and in the same row with $a, b, c .01$ is $25 \%$ diluted of Epichloë endophyte, 02 is $50 \%$ and 03 is undiluted.

control during 2-8 weeks (Figure 1). The mean plant height of the treatment is $5.4,12.8,17.4$, and $21.4 \mathrm{~cm}$ at $2,4,6$, and 8 week, respectively. The plant height difference among the 3 treatments was not significant $(P>0.05)$ during $2-4$ weeks, from 4 to 8 weeks plants treated with Et03 and Et02 showed no significant $(P>0.05)$ difference, but the difference between plants treated with Et03 and Eb03 was significant $(P<0.05)$. The height of plants treated with Et03 is higher than that of plants subjected to other treatments during $2-8$ weeks, and significantly $(P<0.05)$ higher than the control of 4.9,11.0, 14.7, and $18.2 \mathrm{~cm}$.

After 2 weeks, the tiller numbers of the treatment and control showed no significant $(P>0.05)$ difference (Figure 2$)$. The tiller number of treated plants was significantly $(P<0.05)$ higher than the control plants during $4-8$ weeks. Plants treated with Et03 had more tillers than the other treatments, however this was not significant $(P>0.05)$ with respect to plants treated with Eb03 and Et02. Treatment with endophyte supernatant resulted in large effects on the formation of tillers during the $4-6$ week period. The tiller number of treated plants was significantly higher than that of the control plants by $29.17,58.33$, and $37.50 \%$, respectively.

At the final harvest after 8 weeks, treatment with endophyte supernatant from Eb03, Et03, and Et02 resulted in a significant $(P<0.05)$ increase of total dry weight, higher than the control seedlings by $37.20,53.63$, and $42.43 \%$, respectively (Figure 3 ). Among the three different treatments, that treated by Et03 was higher than the others, the effect of the other endophytes was not significant $(P>0.05)$.

\section{DISCUSSION}

Biological control of plant diseases is an important effect observed on grasses infected by Epichloë endophytes although there are mixed results. It is observed that epiphyllous mycelial nets in some endophyte-grass associations may play a role in defense against pathogens by niche exclusion (Moy et al., 2000). The research methods of endophytic fungi interaction with pathogenic fungi are mainly concentrated in dual-culture on plate, PDB trials, in vitro inoculation, vital inoculation and field trial. The present work, to our knowledge, is the first report of the protective effect of Epichloë endophytes against seed-borne fungi, and resulting in increased seed germination and plant growth.

Previous research has shown that Epichloë can have inhibition activity against pathogenic fungi such as Alternaria, Bipolaris, Fusarium, Cladosporium, Pythium, Curvularia, Drechslera, Rhizoctonia, and so on (Holzmann-Wirth et al., 2000; Nan and Li, 2004; Li et al., 2007a; Tian et al., 2008). In this work we found that, compared with controls, the Epichloë endophyte increases interim germination, germination rate, coleoptile length, radicle length and dry weight of E. sibiricus to varying degrees when plants are under stress from seed-borne fungi such as A. alternata, B. sorokiniana, F. avenaceum and Fusarium sp.

Similar results were obtained by New Zealand scientists, which ranged from nil to strong inhibition on growth and conidial germination of grass-pathogenic fungi by E. festucae var. lolii ( $N$. lolii) and endophytes in in vitro tests (Christensen and Latch, 1991; Christensen et al., 1991). A previous study with E. coenophiala (N. coenophialum) showed effective inhibition of growth of A. alternata (White and Cole, 1985); E. festucae var. lolii (N. lolii) effectively inhibited Drechslera spp. (HolzmannWirth et al., 2000). Nan and Li (2000) showed that detached leaves of $\mathrm{E}+$ Elymus cylindricus had fewer and smaller lesions than those on E- plants inoculated with A. alternata, $F$. avenaceum. These studies addressed antifungal activities of endophyte in vitro or on detached leaves of other grass species. That the total lengths of lesions on detached leaves were greater $(P<0.05)$ on $\mathrm{E}$ - plants than on $\mathrm{E}+$ plants when inoculated with the plant pathogens A. alternata, B. sorokiniana, C. lunata, F. acuminatum, F. avenaceum, and 10 other species of pathogenic fungi. Although differences between $\mathrm{E}+$ and $\mathrm{E}-$ were not consistently significant at all sample times (days after inoculation) in detached leaves. The numbers of lesions were greater $(P<0.05)$ and the lesions were larger $(P<0.05)$ on intact $\mathrm{E}$ - plants than on intact $\mathrm{E}+$ plants for the pathogens of four pathogens (A. alternata, B. sorokiniana, Curvularia lunata and $F$. avenaceum) when living plants were studied (Tian et al., 2008).

This study found that compared with the seeds without soaking with endophytic fungi supernatants, the plant height, tiller and biomass all have different degrees of increase. This is similar to the Epichloë endophyte induced improvments in plant height, tillering and biomass of grasses, including A. inebrians (Nan and Li, 2000), F. arundinacea (Joost, 1995) and L. perenne (Clay, 1987). Latch et al. (1985) reported that L. perenne infected with E. festucae var. lolii (N. lolii) resulted in dry weights nearly $38 \%$ higher than the non-infected $L$. perenne, and the leaf area, number of branches and root dry weight were also significantly $(P<0.05)$ higher than the control. Compared with the un-infected $F$. arundinacea, E. coenophiala (N. coenophialum), endophyte significantly $(P<0.05)$ increases the production, performance and the grass coverage by $20-$ $30 \% 4$ months after sowing (Joost, 1995). The endophytic fungi can increase forage yield of $22-55 \%$, the number of tillers $20-45 \%$ and the seed weight 26-41\% (Clay et al., 1993). Nan and Li (2000) founds that endophytic fungi infection 


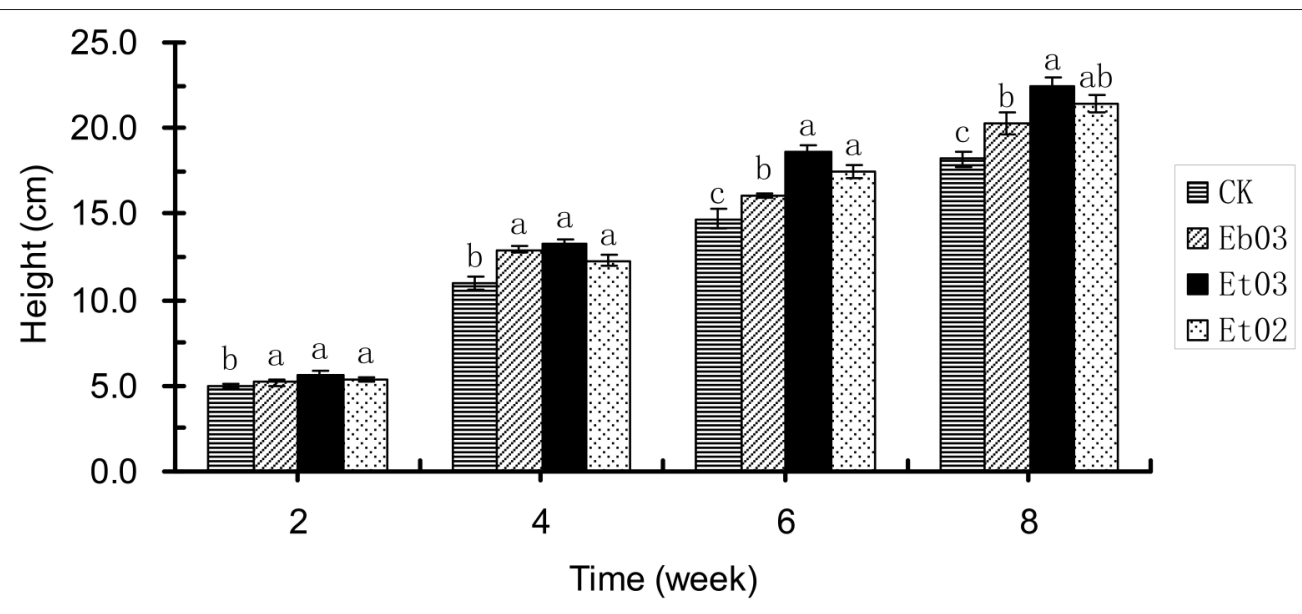

FIGURE 1 | Effects of Epichloë endophyte on plant height of Elymus sibiricus. Significant differences at the 0.05 level are indicated within a time by different letters above bars. Values are means of five replicates \pm SE.

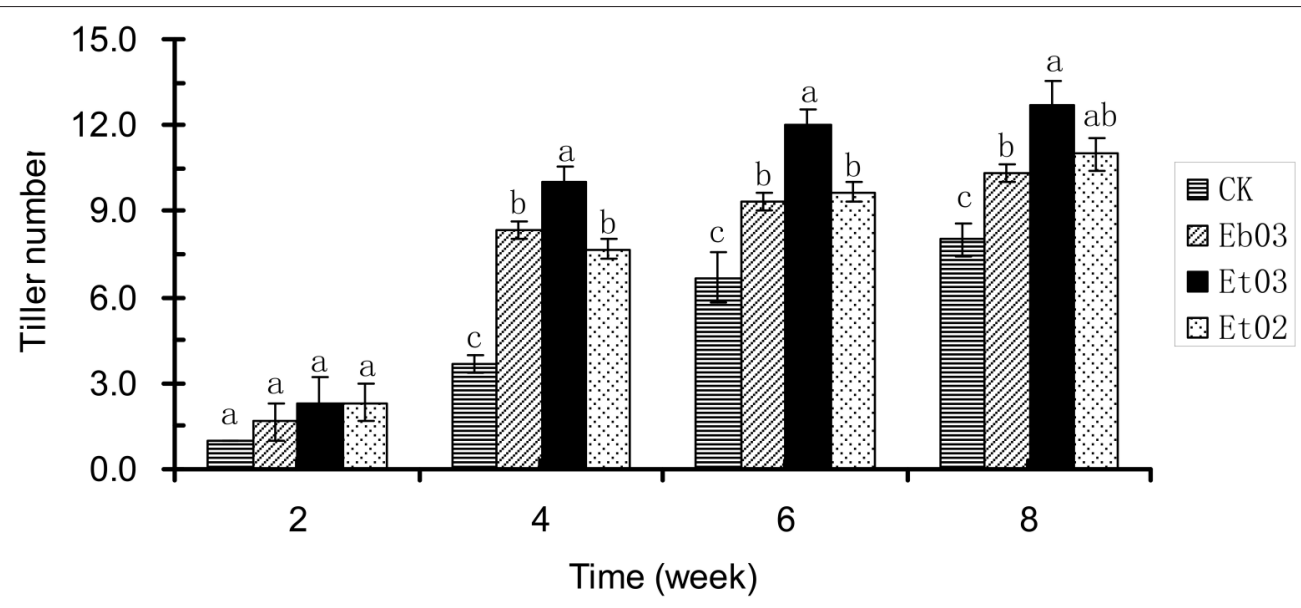

FIGURE 2 | Effects of Epichloë endophyte on tiller numbers of Elymus sibiricus. Significant differences at the 0.05 level are indicated within a time by different letters above bars. Values are means of five replicates \pm SE.

of $H$. bogdanii significantly $(P<0.05)$ promotes the growth of host plants, the plant tiller number increased by $136.8 \%$, herbage yield increased by $33.3 \%$ and root dry weight increased by $30 \%$. In filed experiments examining E. cylindricus, the endophyte increased the tiller number by $84.5 \%$, the above ground dry weight increased by $278.7 \%$ and the tiller weight increased by $105.3 \%$. A potted plant experiment showed that the extracts from $\mathrm{E}+A$. inebrians remarkably enhanced the growth of F. arundacea, L. perenne and P. pratensis (Yang et al., 2010).

Tillering of grasses is controlled, amongst other things, by indole acetic acid and other plant hormones. Endophytic fungi have the ability to produce indole acetic acid, this might be one of the reasons for the promotion of tillering in infected plants (West and Gwinn, 1993). However, in this study, there were no significant $(P>0.05)$ differences of plant tiller number between plants that were treated with endophyte exudate and untreated controls in the 2 weeks under greenhouse conditions. This absence of effect at the $P<0.05$ level might be due to low levels of indole acetic acid being produced by the seeding at this early stage of growth.

Based on the results of the germination test presented here, the seed germination decreased with increased culture concentration of the endophytic fungi, similar to the results of Huang et al. (2010) research results. They reported that the water extraction of the $\mathrm{E}+A$. inebrians had significant inhibitory effects on seed germination and seedling growth of S. capillata and P. sphondylodes using a Petri dish-paper germination method. Inhibition is also seen on the seed germination rate of $L$. perenne and bud length of $P$. pratensis by the same method. But the potted experiment showed that the grass powder of $\mathrm{E}+A$. inebrians accelerated plant growth and initial seedling emergence rates of L. perenne and $P$. pratensis. It is speculated that the ergonovine and ergine 


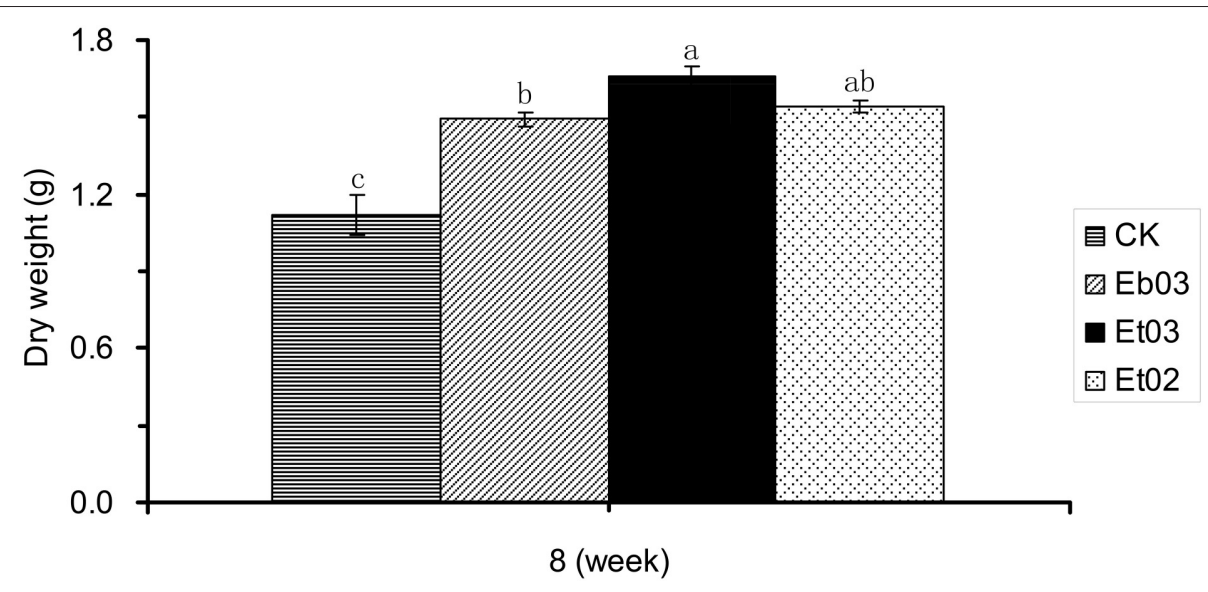

FIGURE 3 | Effects of Epichloë endophyte on dry weight of Elymus sibiricus. Significant differences at the 0.05 level are indicated within a time by different letters above bars. Values are means of five replicates \pm SE.

concentration from A. inebrians/E. gansuensis (N. gansuense) may be responsible for this effect (Yang et al., 2010). Petroski et al. (1990) reported that loline has strong allelopathy to annual ryegrass and alfalfa. The loline produced by F. arundinacea has higher allelopathy to its competitors (Malinowski and Belesky, 2000). The suggestion that the inhibitory effects of $\mathrm{Eg}$ and $\mathrm{Eb}$ on seed germination due to their heigher alkaloid concentrations requires further study.

Here we have demonstrated that fungal culture supernatants can greatly promote germination and subsequent plant growth under seed-borne fungi stress. However, high concentrations can suppress growth, this action appears to be complex. The interactive mechanisms of Epichloë endophyte and seedborne fungi require further study, and the effective range of concentrations of different endophyte exudates needs to be determined. This may eventually provide insight into strategies for the improvement of field performance and stress tolerance in grasses of forage and turf.

\section{REFERENCES}

Bonos, S. A., Wilson, M. M., Meyer, W. A., and Reed, F. C. (2005). Suppression of red thread in fine fescues through endophyte-mediated resistance. Appl. Turfgrass Sci. 2, 1094-1097. doi: 10.1094/ATS-2005-0725-01-RS

Christensen, M. J. (1996). Antifungal activity in grasses infected with Acremonium and Epichloë endophytes. Aust. Plant Pathol. 5, 186-191. doi: 10.1071/AP96032

Christensen, M. J., and Latch, G. C. M. (1991). Variation among isolates of Acremonium endophytes (A. coenophialum and possibly A. typhinum) from tall fescue (Festuca arundinacea). Mycol. Res. 95, 1123-1126. doi: 10.1016/S0953-7562(09)80558-3

Christensen, M. J., Latch, G. C. M., and Tapper, B. A. (1991). Variation within isolates of Acremonium endophytes from perennial rye-grasses. Mycol. Res. 95, 918-923. doi: 10.1016/S0953-7562(09)80087-7

Clarke, B. B., White, J. F., Hurley, R. H., Torres, M. S., Sun, S., and Huff, D. F. (2006). Endophyte-mediated suppression of dollar spot disease in fine fescues. Plant Dis. 90, 994-998. doi: 10.1094/PD-90-0994

Clay, K. (1987). Effects of fungal endophytes on the seed and seedling biology of Lolium perenne and Festuca arundinacea. Oecologia 73, 358-362. doi: $10.1007 / \mathrm{BF} 00385251$

\section{AUTHOR CONTRIBUTIONS}

X-ZL designed and performed experiments, analyzed the data and wrote the manuscript. C-JL designed experiments, polished manuscript, provided reagents and experimental equipment. M-LS, XY, and QC performed experiments and analyzed the data. WS analyzed the data and polished manuscript. Z-BN provided reagents and experimental equipment. All authors reviewed the manuscript.

\section{ACKNOWLEDGMENTS}

This study is supported by National Basic Research Program of China (2014CB138702), the Natural Science Foundation of China (31372366), Program for Changjiang Scholars and Innovative Research Team in University of China (IRT17R50), the 111 project (B12002) and Fundamental Research Funds for the Central Universities (lzujbky-2016-bt10, lzujbky-2017 $-\mathrm{kb} 11)$.

Clay, K., Marks, S., and Cheplick, G. P. (1993). Effects of insect herbivory and fungal endophyte infection on competitive interactions among grasses. Ecology 74, 1767-1777. doi: 10.2307/1939935

Clay, K., and Schardl, C. (2002). Evolutionary origins and ecological consequences of endophyte symbiosis with grasses. Am. Nat. 160, S99-S127. doi: $10.1086 / 342161$

Gwinn, K. D., and Bernard, E. C. (1988). Acremonium coenophialum does not affect Rhizoctonia zeae growth in vitro or in vivo. Phytopathology 78, 15-24.

Hahn, H., McManus, M. T., Warnstorff, K., Monahan, B. J., Young, C. A., Davies, E., et al. (2008). Neotyphodium fungal endophytes confer physiological protection to perennial ryegrass (Lolium perenne L.) subjected to a water deficit. Environ. Exp. Bot. 63, 183-199. doi: 10.1016/j.envexpbot.2007. 10.021

Holzmann-Wirth, A., Dapprich, P., Eierdanz, S., Heerz, D., and Paul, V. H. (2000). "Anti-fungal substances extractedfrom Neotyphodium endophytes," in Proceedings of The 3rd International Conference on Harmful and Beneficial Microorganisms in Grassland, eds V. H. Paul and P. D. Dapprich (Soest: Pasture and Turf).

Huang, X., Li, C. J., Nan, Z. B., Yang, S., and Chai, Q. (2010). Effects of Achnatherum inebrians infected with Neotyphodium endophyte on 
accompanying species of Stipa capillata and Poa sphondylodes. Acta Pratacult. Sin. 19, 87-93. doi: 10.3724/SP.J.1105.2010.00087

Joost, R. E. (1995). Acremonium in fescue and ryegrass: boon or bane? A review. J. Anim. Sci. 73, 881-888. doi: 10.2527/1995.733881x

Kuldau, G. A., Liu, J. S., White, J. F. Jr., Siegel, M. R., and Schardl, C. L. (1997). Molecular systematics of Clavicipitaceae supporting monophyly of genus Epichloë and form genus Ephelis. Mycologia 89, 431-441. doi: 10.2307/3761037

Kuldau, G., and Bacon, C. (2008). Clavicipitaceous endophytes: their ability to enhance resistance of grasses to multiple stresses. Biol. Control 46, 57-71. doi: 10.1016/j.biocontrol.2008.01.023

Latch, G. C. M., Christensen, M. J., and Gaynor, D. (1985). Aphid detection of endophyte infection in tall fescue. N.Z.J. Agric. Res. 28, 129-132. doi: 10.1080/00288233.1985.10427006

Leuchtmann, A. (1993). Systematics, distribution, and host specificity of grass endophytes. Nat. Toxins 1, 150-162. doi: 10.1002/nt.2620010303

Leuchtmann, A., Bacon, C. W., Schardl, C. L., White, J. F., and Tadych, M. (2014). Nomenclatural realignment of Neotyphodium species with genus Epichloë. Mycologia 106, 202-215. doi: 10.3852/13-251

Li, C. J., Zhang, X. X., and Li, F. (2007a). "Disease and pests resistance of endophyte infected and non-infected drunken horse grass," in Proceedings of the 6th International Symposium on Fungal Endophytes of Grasses, eds A. J. Popay and E. R. Thom (Dunedin: Grassland Association).

Li, C. J., Gao, J. H., and Nan, Z. B. (2007b). Interactions of Neotyphodium gansuense, Achnatherum inebrians, and plant-pathogenic fungi. Mycol. Res. 111, 1220-1227. doi: 10.1016/j.mycres.2007.08.012

Li, C. J., Nan, Z. B., Paul, V. H., Dapprich, D. D., and Liu, Y. (2004). A new Neotyphodium species symbiotic with drunken horse grass (Achnatherum inebrians) in China. Mycotaxon 90, 141-147.

Ma, X., Chen, S. Y., Bai, S. Q., Zhang, X. Q., Li, D. X., Zhang, C. B., et al. (2012). RAPD analysis of genetic diversity and population structure of Elymus sibiricus (Poaceae) native to the southeastern Qinghai-Tibet Plateau, China. Genet. Mol. Res. 11, 2708-2718. doi: 10.4238/2012.June.27.5

Malinowski, D. P., and Belesky, D. P. (2000). Adaptations of endophyteinfected coolseason grasses to environmental stresses: mechanisms of drought and mineral stress tolerance. Crop Sci. 40, 923-940. doi: $10.2135 /$ cropsci2000.404923x

Moy, M., Belanger, F., Duncan, R., Freehoff, A., Leary, C., Meyer, W., et al. (2000). Identification of epiphyllous mycelial nets on leaves of grasses infected by Clavicipitaceous endophytes. Symbiosis 28, 291-302.

Nan, Z. B., and Li, C. J. (2000). "Neotyphodium in native grasses in China and observations on endophyte/hosts interactions," in Neotyphodium in Coolseason Grasses, eds C. A. Roberts, C. P. West, and D. A. Spiers (Ames, IA: Blackwell Publishing Ltd.) 163-185.

Nan, Z. B., and Li, C. J. (2004). Roles of the grass-Neotyphodium association in pastoral agriculture systems. Acta Ecol. Sin. 24, 605-616.

Omacini, M., Chaneton, E. J., Ghersa, C. M., and Müller, C. B. (2001). Symbiotic fungal endophytes control insect host-parasite interaction webs. Nature 409, 78-81. doi: 10.1038/35051070

Pennell, C. G. L., and Rolston, M. P. (2012). "Novel uses of grass endophyte technology," in Proceedings of the 8th International Symposium on Fungal Endophyte of Grasses, eds Z. B. Nan and C. J. Li (Lanzhou).

Pennell, C. G. L., Rolston, M. P., De Bonth, A., Simpson, W. R., and Hume, D. E. (2010). Development of a bird-deterrent fungal endophyte in turf tall fescue. $N$. Z. J. Agric. Res. 53, 145-150. doi: 10.1080/00288231003777681

Petroski, R. J., Dornbos, D. L. Jr., and Powell, R. G. (1990). Germination and growth inhibition of annual ryegrass (Lolium multiflorum L.) and alfalfa (Medicago sativa $\mathrm{L}$.) by loline alkaloids and synthetic $\mathrm{N}$-acylloline derivatives. J. Agric. Food Chem. 38, 1716-1718. doi: 10.1021/jf00098a019

Porras-Alfaro, A., and Bayman, P. (2010). Hidden fungi, emergent properties: endophytes and microbiomes. Annu. Rev. Phytopathol. 49, 291-315. doi: 10.1146/annurev-phyto-080508-081831
Schardl, C. L. (2001). Epichloë festucae and related mutualistic symbionts of grasses. Fungal Genet. Biol. 33, 69-82. doi: 10.1006/fgbi.2001.1275

Schardl C. L. (2009). "Fungal endophytes in Lolium and Festuca species," in Molecular Breeding of Forage and Turf, eds T. Yamada and G. Spangenberg, (New York, NY: Springer), 285-298. doi: 10.1007/978-0-387-79144-9_26

Schardl, C. L., Leuchtmann, A., and Spiering, M. J. (2004). Symbioses of grasses with seedborne fungal endophytes. Annu. Rev. Plant Biol. 55, 315-340. doi: 10.1146/annurev.arplant.55.031903.141735

Scott, B. (2001). Epichloë endophytes: fungal symbionts of grasses. Curr. Opin. Microbiol. 4, 393-398. doi: 10.1016/S1369-5274(00)00224-1

Song, H., and Nan, Z. (2015). Origin, divergence, and phylogeny of asexual Epichlö̈ endophyte in Elymus species from western China. PLoS ONE 10:e0127096. doi: 10.1371/journal.pone.0127096

Song, H., Song, Q. Y., Li, X. Z., and Nan, Z. B. (2015). Are Epichloë endophytes specific to Elymus grass hosts? Genet. Mol. Res. 14, 17463. doi: 10.4238/2015.December.21.17

Tian, P., Nan, Z. B., and Li, C. J. (2008). Effect of the endophyte Neotyphodium lolii on susceptibility and host physiological response of perennial ryegrass to fungal pathogens. Eur. J. Plant Pathol. 122, 593-602. doi: 10.1007/s10658-0089329-7

van Zijll de Jong, E., Guthridge, K. M., Spangenberg, G. C., and Forster, J. W. (2011). Sequence analysis of SSR-flanking regions identifies genome affinities between pasture grass fungal endophyte taxa. Int. J. Evol. Biol. 2011:921312. doi: 10.4061/2011/921312

Vignale, M. V., Astiz-Gassó, M. M., Novas, M. V., and Iannone, L. J. (2013). Epichloid endophytes confer resistance to the smut Ustilago bullata in the wild grass Bromus auleticus (Trin.). Biol. Control 67, 1-7. doi: 10.1016/j.biocontrol.2013.06.002

Wäli, P. R., Helander, M., Nissinen, O., and Saikkonen, K. (2006). Susceptibility of endophyte-infected grasses to winter pathogens (snow molds). Botany 84, 1043-1051. doi: 10.1139/b06-075

West, C. P., and Gwinn, K. D. (1993). "Role of Acremonium in drought, pest and disease tolerances of grasses," in Proceeding of the 2 nd International symposium on Acremonium/Grass Interactions: Plenary Papers. eds D. E. Hume, G. C. Latch and H. S. Easton (Paimerston North).

White, J. F., and Cole, G. T. (1985). Endophyte-host association in forage grasses. III. in vitro inhibition of fungi by Acremonium coenophialum. Mycologia 77, 487-489.

Xie, F. X., Ren, A. Z., Wang, Y. H., Lin, F., and Gao, Y. B. (2008). A comparative study of the inhibitive effect of fungal endophytes on turf grass fungus pathogens. Acta Ecol. Sin. 28, 3913-3920.

Yan, J., Bai, S., Ma, X., and Gan, Y. (2007). Genetic diversity of Elymus sibiricus and its breeding in China. Chin. Bull. Bot. 24, 226-231.

Yang, S., Huang, X., Chai, Q., Li, C. J., and Nan, Z. B. (2010). Allelopathic effects of endophytic fungi of Achnatherum inebrians Keng on the seed and seedling of three turf grasses. Acta Agrestia Sin. 1:017.

Zhang, X. X., Li, C. J., Nan, Z. B., and Matthew, C. (2012). Neotyphodium endophyte increases Achnatherum inebrians (drunken horse grass) resistance to herbivores and seed predators. Weed Res. 52, 70-78. doi: 10.1111/j.1365-3180.2011.00887.x

Conflict of Interest Statement: The authors declare that the research was conducted in the absence of any commercial or financial relationships that could be construed as a potential conflict of interest.

Copyright (C) 2017 Li, Song, Yao, Chai, Simpson, Li and Nan. This is an open-access article distributed under the terms of the Creative Commons Attribution License (CC $B Y)$. The use, distribution or reproduction in other forums is permitted, provided the original author(s) or licensor are credited and that the original publication in this journal is cited, in accordance with accepted academic practice. No use, distribution or reproduction is permitted which does not comply with these terms. 